\title{
Large Empty Sella with an Intrasellar Herniation of an Elongated Third Ventricle
}

\author{
-Case Report-
}

\author{
Hideo Osada, Takahito Miyazawa, Akira OHnuki, Nobusuke TsuzUKI, \\ Hiroshi NAWASHIRO, and Katsuji SHIMA
}

Department of Neurosurgery, National Defense Medical College, Tokorozawa, Saitama

\begin{abstract}
A 73-year-old female presented with a large empty sella with herniation of an elongated third ventricle concomitant with herniation of the surrounding subarachnoid space into the sella, manifesting as visual impairment and amenorrhea without galactorrhea. Magnetic resonance imaging and computed tomography cisternography clearly showed the large empty sella, without evidence of either hydrocephalus or benign intracranial hypertension, which is extremely rare.
\end{abstract}

Key words: empty sella, herniation, third ventricle, pituitary adenoma, magnetic resonance imaging, computed tomography cisternography

\section{Introduction}

Empty sella is defined as extension of the subarachnoid space through an incomplete diaphragma sellae into the sella. Enlargement of the sella or remodeling of the pituitary gland may also be present. We report a rare case of a large empty sella due to protrusion of the elongated third ventricle into the sella and discuss the pathogenesis of this disorder.

\section{Case Report}

A 73-year-old female, who was treated by an ophthalmologist because of glaucoma and senile cataracta, was referred to our affiliated hospital for evaluation of bilateral ophthalmic pain beginning 3 days previously. Her axillar and pubic hair had been scanty from the age of 20 years, and she had had amenorrhea without galactorrhea from the age of 25 years. She was married, but could not have children. She had been suffering from hypertension for a long time.

On admission, physical and neurological examinations found no abnormalities except for visual symptoms. Bitemporal hemianopsia had already

Received December 24, 1998; Accepted March 15, 1999 been confirmed more than 10 years before by the ophthalmologist. Visual impairment due to cataracta or glaucoma was recognized. Papilledema was not observed. Cerebrospinal fluid (CSF) pressure was found to be normal by lumbar puncture.

Skull roentgenography showed balloon-like enlarged sella with thinning and partial destruction of the sellar floor (Fig. 1). Computed tomography (CT) demonstrated the sella as a low density area, which suggested the presence of an empty sella. Magnetic resonance (MR) imaging showed herniation of the elongated third ventricle (Fig. 2A-C). Expanded chiasmal and infundibular recesses were detected in the sella. The optic nerve, chiasm, and optic tract were displaced downward. The pituitary gland was not clearly discernible. No obvious signs of pituitary adenoma or hydrocephalus were detected. CT cisternography revealed a complete negative defect in the sella due to the herniated third ventricle, which was surrounded by the herniated subarachnoid space filled with Isovist (Schering AG, Berlin, Germany) (Fig. 2D). Cerebral angiography showed only a fusiform aneurysmal dilatation of the left carotid bifurcation.

Although hormonal examination or treatment for the empty sella were not permitted by the patient, long-standing insufficiency of the pituitary function is almost certain because of the presence of amenorrhea, and the scanty axillar and pubic hair. 

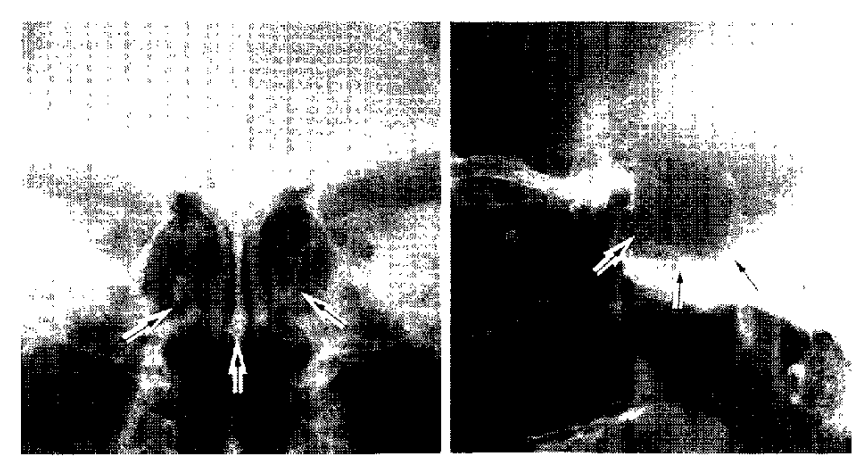

Fig. 1 Skull roentgenograms of the sella, anteroposterior view (left) and lateral view (right), showing the balloon-like enlarged sella (arrows) with thinning and partial destruction of the sellar floor.
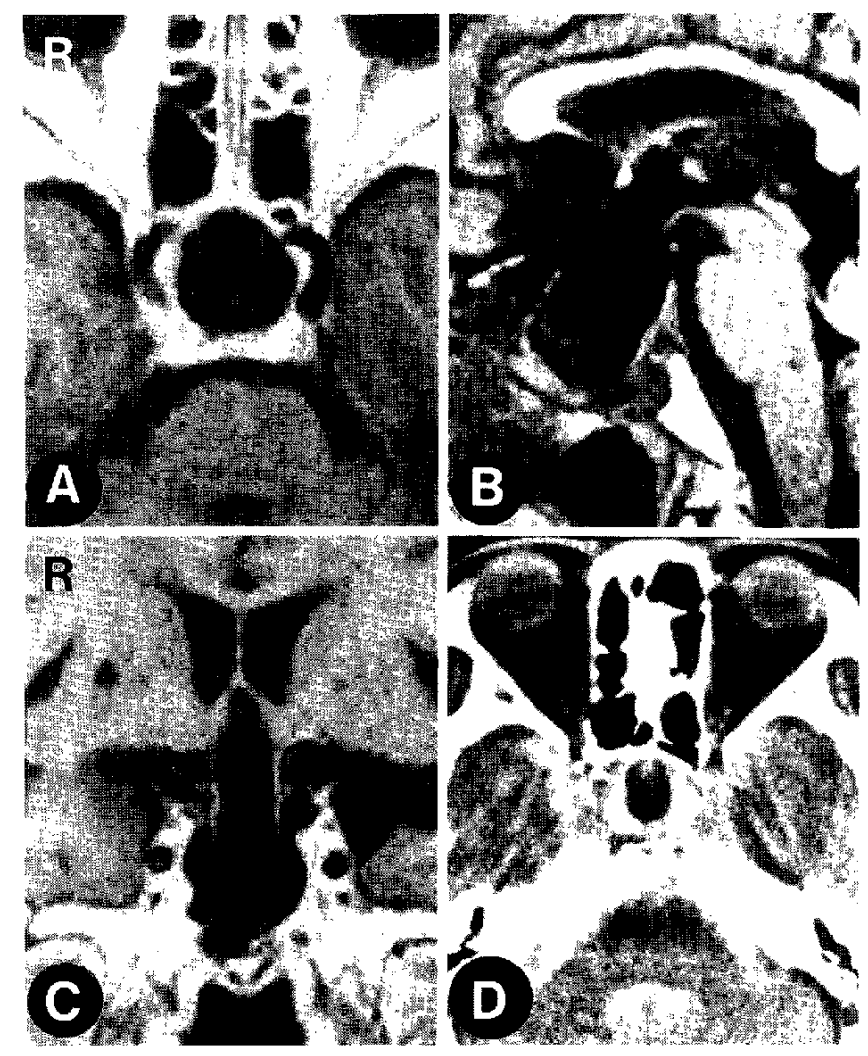

Fig. 2 Axial (A), sagittal (B), and coronal (C) $\mathbf{T}_{\mathbf{1}^{-}}$ weighted magnetic resonance images, and axial computed tomography cisternogram 3 hours after intrathecal administration of 10 ml Isovist (D), showing intrasellar herniation of the elongated third ventricle surrounded by the subarachnoid space that has concomitantly herniated into the sella. The chiasmal recess, infundibular recess, and optic nerves are pulled down into the sella.

\section{Discussion}

Normally, the chiasm and chiasmal recess of the third ventricle are located at 7 to $12 \mathrm{~mm}$ above the sellar diaphragm. In the presence of a diaphragmatic deficiency, the subarachnoid space displaces the pituitary gland down into the sellar floor, and the hypophyseal stalk is also retracted. As a result, the third ventricle wall is thinned and pulled down into the sella. ${ }^{3,9)}$ Hydrocephalus or benign intracranial hypertension (or pseudotumor cerebri) can easily promote the process of evagination of the third ventricle. ${ }^{1,5,6,10)}$ Most cases of evagination of the third ventricle into the sella have been accompanied by such disorders. ${ }^{1,6,10)}$ Pituitary adenoma may also cause third ventricle evagination. ${ }^{87}$ Shrinkage of a pituitary adenoma following radiation therapy and apoplexy may allow the subarachnoid space, and rarely the third ventricle floor, to herniate into the sella through the incomplete diaphragm. ${ }^{8,11}$ !

Persistent infundibular recess, which is thought to be a congenital anomaly, has been reported in only a few cases. ${ }^{10,12)}$ A common feature is a tunnelshaped extension of the anterior third ventricle into the sella, ending in a round pocket within the sella. All reported cases were associated with hydrocephalus without neurological symptoms, and all cases except one had no associated intrasellar arachnoidcele. ${ }^{121}$ In the present case, since the herniated third ventricle in the sella was surrounded by the subarachnoid space without evidence of either hydrocephalus or pseudotumor cerebri, the disorder was not identical with persistent infundibular recess.

The pathogenesis of our case could involve two possible mechanisms. First, the large congenital deficiency of the diaphragma sellae allowed the long-standing normal pulsatile force of the CSF caused both the subarachnoid space and the third ventricle floor to herniate slowly into the sella., ${ }^{2,3]}$ Systemic hypertension may also be involved in this mechanism by intermittently increasing the intracranial pressure. ${ }^{7}$ The other possible mechanism is a secondary event as a result of shrinkage of the pituitary adenoma due to either silent apoplexy or burning-out. Our patient had scanty axillar and pubic hair, and amenorrhea without galactorrhea from the third decade, which is obvious evidence of pituitary dysfunction. This suggests she had a pituitary adenoma during her life, because clinical endocrine dysfunction is generally believed to be rare in adult primary empty sella patients in spite of severe compression and flattening of the pituitary gland. ${ }^{4 !}$ Regardless of the pathogenesis, our case showed very unusual MR imaging and CT cisternography findings of a large empty sella with an elongated 
third ventricle herniating into the sella without either hydrocephalus or pseudotumor cerebri. ${ }^{3)}$

\section{Acknowledgment}

We express our deep gratitude to Dr. Isamu Fujisaki, president of Fujisaki Hospital, Tokyo, for kindly allowing us to report the present case.

\section{References}

1) Asai JI, Fujimoto T, Fukushima Y: [Empty sella as an intrasellar herniation of the third ventricle secondary to spontaneous degeneration of a prolactinoma]. No Shinkei Geka 22: 241-246, 1994 (Jpn, with Eng abstract)

2) Bergland RM, Ray BS, Torack RM: Anatomical variations in the pituitary gland and adjacent structures in 225 human autopsy cases. J Neurosurg 28: 93-99, 1968

3) Corrales M, Torrealba G: The third ventricle. Normal anatomy and changes in some pathological conditions. Neuroradiology 11: 271-277, 1976

4) Ekblom M, Ketonen L, Kuuliala I, Pelkonen R: Pituitary function in patients with enlarged sella turcica and primary empty sella syndrome. Acta Med Scand 209: 31-35, 1981

5) Foley KM, Posner JB: Does pseudotumor cerebri cause the empty sella syndrome? Neurology 25: 565569,1975

6) Kaufman B, Tomsak RL, Kaufman BA, Arafah BU, Bellon EM, Selman WR, Modic MT: Herniation of the suprasellar visual system and third ventricle into empty sellae: Morphologic and clinical considerations. AJR Am J Roentgenol 152: 597-608, 1989

7) Kaye AH, Tress BM, Brownbill D, King J: Intracranial pressure in patients with the empty sella syndrome without benign intracranial hypertension. I Neurol Neurosurg Psychiatry 45: 209-216, 1982

8) Keyaki A, Makita Y, Nabeshima S, Motomochi M, Itagaki T, Tei T: [Secondary empty sella syndrome: report of three cases and review of the literature]. No Shinkei Geka 10: 1189-1194, 1982 (Jpn, with Eng abstract)

9) Mortara R, Norrell $H$ : Consequences of a deficient sellar diaphragm. J Neurosurg 32: 565-573, 1970

10) Nagata $K$, Joshita $H$, Matsui $T$, Kaizu $H$, Ishikawa $T$, Shigeno T, Asano T: Primary empty sella syndrome caused by an abnormal dilatation of the optic recess. Surg Neurol 31: 323-329, 1989

11) Tomonaga $M$, Fukushima T: [Headache, visual disturbance and amblyopic attack associated with sellar enlargement - primary empty sella syndrome]. No Shinkei Geka 6: 1145-1154, 1978 (Jpn, with Eng abstract)

12) Vallee B, Besson G, Person H, Mimassi N: Persisting recessus infundibuli and empty sella. Case report. I Neurosurg 57: 410-412, 1982

Address reprint requests to: T. Miyazawa, M.D., Department of Neurosurgery, National Defense Medical College, 3-2 Namiki, Tokorozawa, Saitama 3598513, Japan. 